\title{
THE EXPRESSION OF NF-кB IN CALCIFYING ODONTOGENIC CYSTS (COCS) AND GHOST CELL ODONTOGENIC CARCINOMAS (GCOCS)
}

\author{
Omneya R. Ramadan*, Manal I. Elnouaem** and Sahar M. ElSheikh**
}

\begin{abstract}
Background: Calcifying odontogenic cysts (COCs) are considered rare odontogenic lesions with a spectrum of behavioral and clinicopathological features. The rare Ghost cell odontogenic carcinoma (GCOC) is the malignant counterpart of (COC). The goal of this work was to study the expression NF- $\mathrm{kB}$ in COCs and GCOCs.

Methods: NF- $\mathbf{~ B ~ e x p r e s s i o n ~ w a s ~ e v a l u a t e d ~ i n ~} 8$ (COCs) and 4 (GCOCs), using immunohistochemical method. Immunostaining was evaluated semi-quantitatively, following to the intensity and extent of staining.

Results: Both cytoplasmic and nuclear and NF- $\kappa \mathrm{B}$ immunopositivity were detected in all COC tissues, as well as in GCOC.

Conclusion: The expression of NF- $\mathbf{k B}$ may represent an important mechanism of tumor development and thus might have a role in the progression of ghost cell lesions.

KEYWORDS: Calcifying odontogenic cyst (COC), Nuclear Factor $\kappa \mathrm{B}$, Ghost cell odontogenic carcinoma (GCOC)
\end{abstract}

\section{INTRODUCTION}

Calcifying odontogenic cysts (COCs) are considered rare odontogenic lesions with a spectrum of behavioral and clinicopathological features. As stated by the new $4^{\text {th }}$ edition of the head and neck tumors WHO classification in 2017, COC is now under odontogenic cysts. COC is a cystic lesion, with a lining of ameloblastoma-like epithelial cells with focal groups of ghost cells. Both types of cells may show projections in the cystic lumina, but with minimal or absent mural proliferations. ${ }^{(1)}$

The rare Ghost cell odontogenic carcinoma (GCOC) is the malignant counterpart of (COC). It can arise as a primary tumor or developing from the lining of calcifying cystic odontogenic tumor [CCOT] or from recurrent dentinogenic ghost cell tumor [DGCT]. (2)

* Lecturer of Oral Pathology, Faculty of Dentistry, University of Alexandria

** Professor of Oral Pathology, Faculty of Dentistry, University of Alexandria 
It constitutes about $0.37 \%$ to $2.1 \%$ of all odontogenic tumors. Presence of ghost cells represents a characteristic histologic feature; these are epithelial cells lacking their nuclei and having just a faint outline of the original nuclei. The ghost cells are not specific; and may be seen in many tumors like pilomatricoma, odontoma, craniopharyngioma, and ameloblastic fibro-odontomes. ${ }^{(3)}$

To date, the clinical and histopathological features of $\mathrm{COC}$ have been described in some studies, but very few studies in the literature targeted its immunohistochemical profile and proliferation activity. Thus, still to be properly understood, the mechanisms of tumor invasiveness and also, progression of the lesion so-called COC. ${ }^{(4)}$

$\mathrm{NF}-\mathrm{\kappa B}$ is one of the members of the family of transcription factors. When it is activated, NF-kB then translocates into the nucleus inducing the expressing of many target genes. That mechanism includes genes involved in tumor metastasis, cell cycle-regulation, vascular endothelial growth factor (VEGF) and others. ${ }^{(4-5)}$ Although the aberrant NF$\kappa \mathrm{B}$ has been proved as important contributing factor in the progression of multiple human tumors and malignancies, ${ }^{(4-7)}$ its role in odontogenic tumors is not exactly known. ${ }^{(8)}$

This study intended at investigating the immuneexpression of NF-kB in CCOT and GCOC.

\section{MATERIAL AND METHODS}

Formalin-fixed paraffin-embedded tissue blocks from (8) cases of COC and (4) cases of GCOC were obtained from the files of the Oral Pathology Department, Faculty of Dentistry, Alexandria University.

Four-microns thick paraffin sections of each case underwent deparaffinization and rehydration in graded alcohols. $\mathrm{H}_{2} \mathrm{O}_{2}(3 \%)$ was used for blocking endogenous peroxidase activity in deparaffinized sections. For antigen to be retrieved, the slides were boiled in $10 \mathrm{mM}$ citrate buffer, $\mathrm{pH} 6.0$ then cooled at room temperature. The sections were subsequently incubated with the primary antibody rabbit polyclonal anti- NF- $\kappa \mathrm{B}$ antibody (Cat
\#RB-9034-R7), (Thermo Scientific, Lab vision, Kalamazoo, MI, USA) in a humified chamber at room temperature. Then slides were washed with phosphate buffer solution (PBS), then treated with the biotin labeled link antibody followed by the streptavidin conjugated horseradish peroxidase. The immunostaining was visualized by immersing the slides in diaminobenzidine. Counterstaining the slides with Mayer's hematoxylin followed. PBS was applied instead of the primary antibody to incubate the negative controls.

Staining was evaluated semi-quantitatively as to intensity and extent of the stain by two qualified examiners blinded to the antibody applied to each section. An x40 objective was used.

\section{RESULTS}

\section{Histopathological findings}

In this research, there were 8 cases $\mathrm{COC}$, and 4 cases GCOC. All lesions of COC included had an obvious cyst space, with odontogenic epithelial lining. The lining epithelium formed of columnar cells at the basal cell layer and an upper more loosely arranged stellate reticulum-like epithelial cell layer. Groups and isolated ghost cells with dystrophic calcifications were present in the lining epithelium and within the connective tissue capsule and cystic spaces. Six cases were simple unicystic with a thin epithelial lining, two to few cells thickness. The other two cases, showed in their lining foci of intraluminal proliferations resembling ameloblastoma but containing ghost cells. Island of odontogenic epithelium or daughter cysts could be seen in the fibrous capsule. GCOC has same features of $\mathrm{COC}$ but with malignant characteristics of cells. Three cases followed a recurring benign COC while one case was presented as de novo. (Fig 1).

\section{Immunohistochemical findings}

NF-kB showed cytoplasmic localization in almost the majority of tumor cells of all COC specimens (Fig 2), and in GCOC, with patchy nuclear staining (Fig 3). The NF-кB nuclear positivity was obviously less than cytoplasmic immunopositivity. 


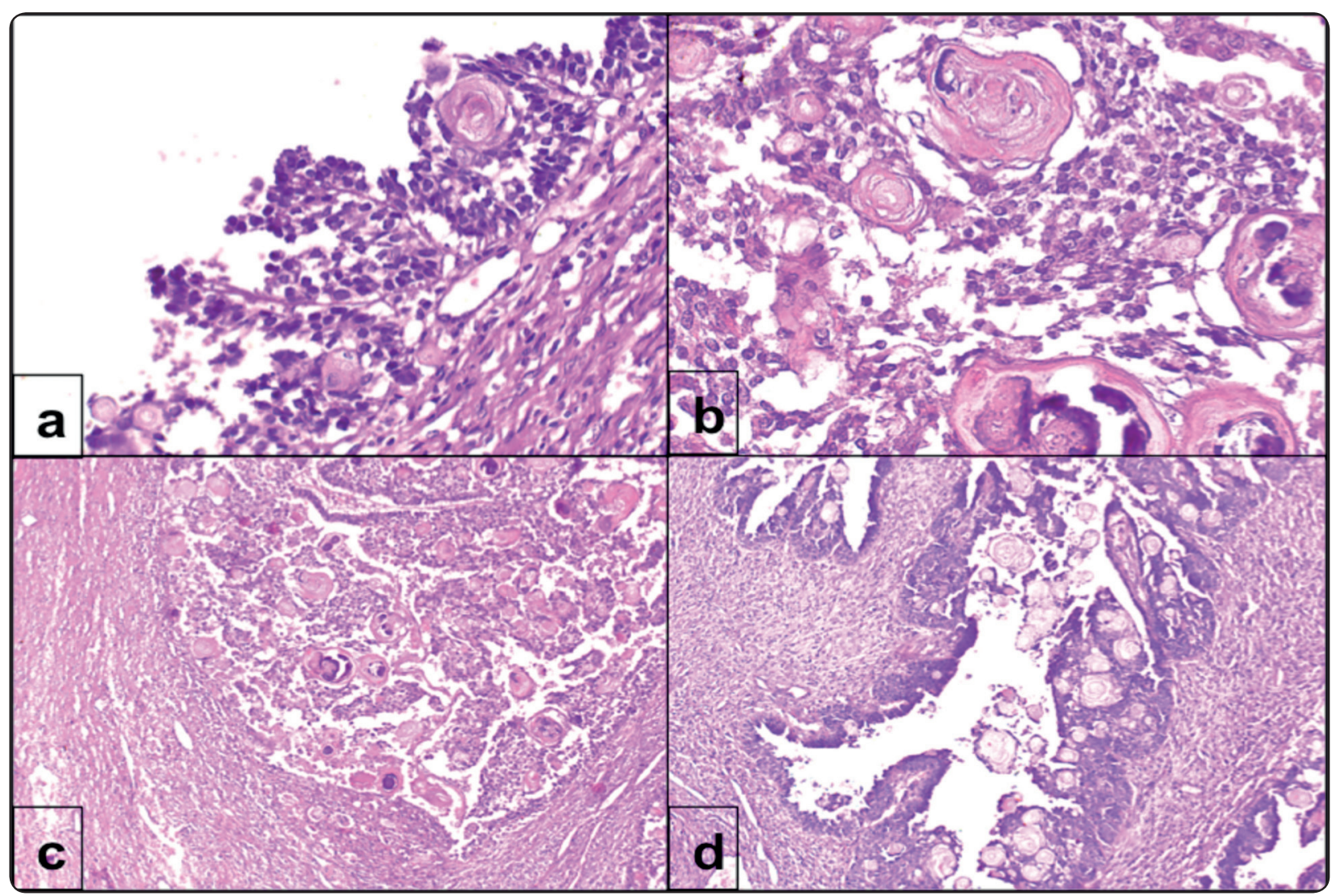

Fig. (1) a) Photomicrograph of COC, cystic lining that shows cuboidal to columnar palisaded basal cells having dark oval nuclei, the epithelium of the upper layers resembling the stellate reticulum cells of the enamel organ (H\&E x 100). b) Islands of odontogenic epithelial cells proliferation with ghost cells are seen (H\&E x100). c,d) Photomicrograph of GCOC. Malignant odontogenic epithelial cells admixed with ghost cells is a prominent characteristic for GCOC (H\&E x100).

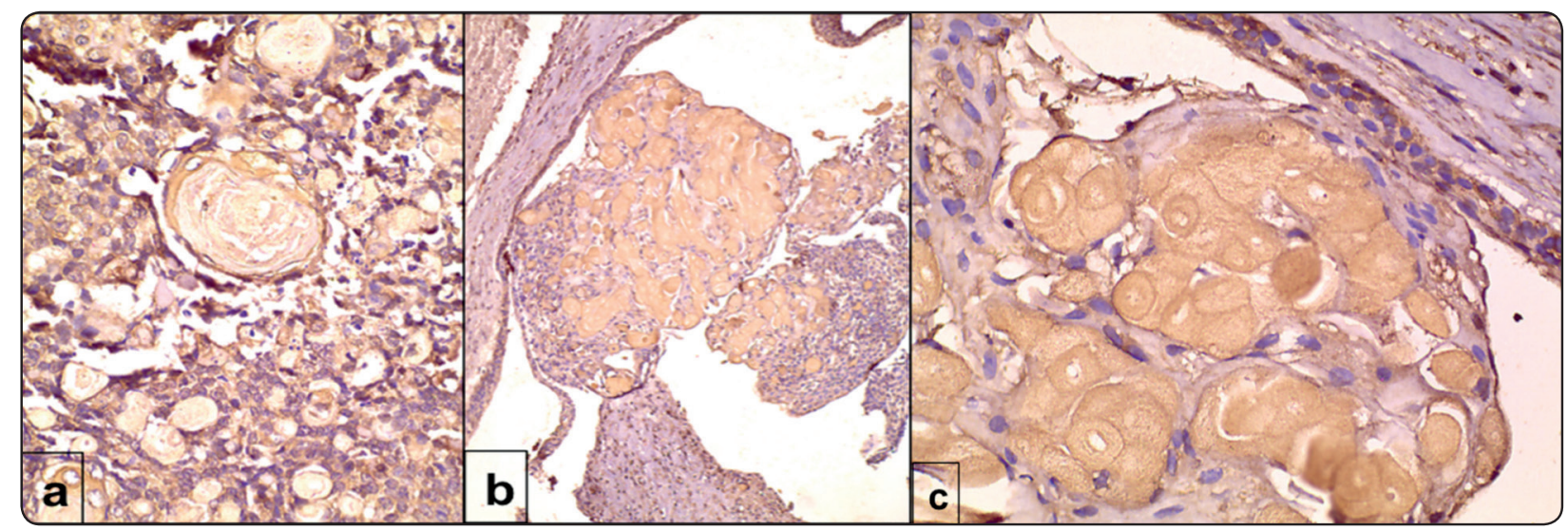

Fig. (2) Photomicrograph showing Immuno-reactivity and cytoplasmic immune-expression of NF-kB in all COC cells. Some positive nuclei could be detected. (a\&b X100, c X 400) 


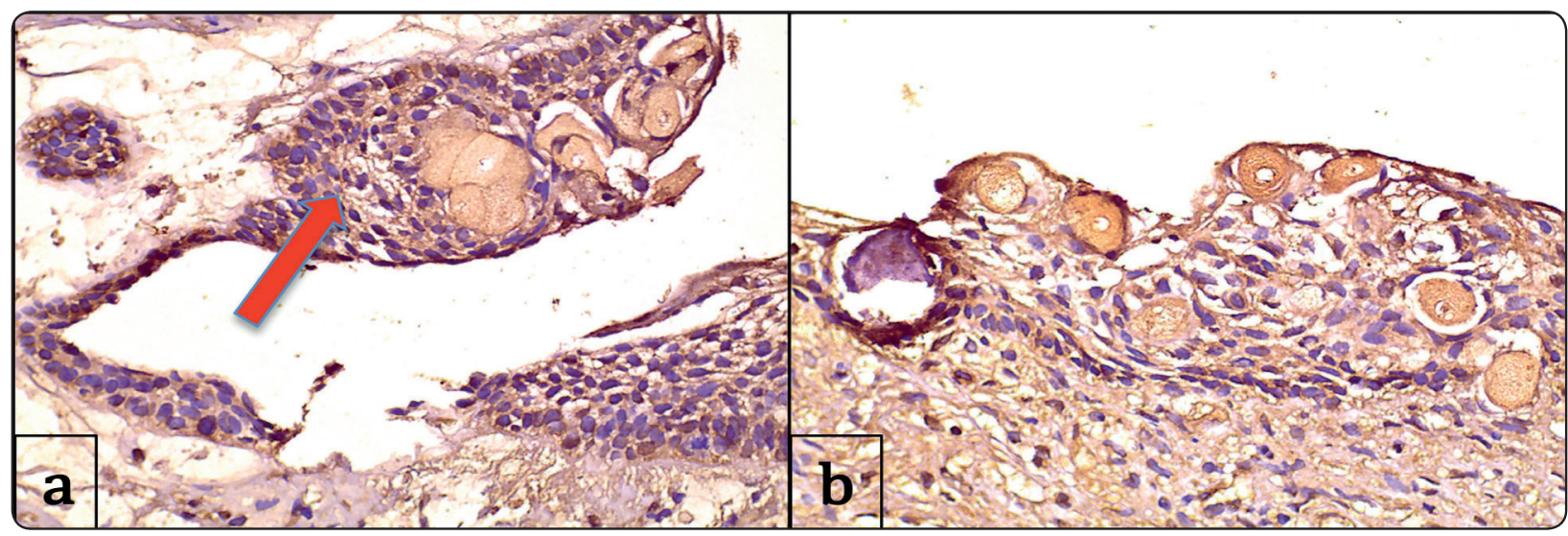

Fig. (3) Photomicrograph showing Immuno-expression of NF-kB in the epithelial lining of GCOC. Cytoplasmic expression is more obvious than the patchy nuclear immune reaction (x100).

\section{DISCUSSION}

$\mathrm{NF}-\mathrm{kB}$ is one of the members of the family of transcription factors. Into normal tissues, NF- $\kappa \mathrm{B}$ exists inactive in cytoplasm till it is triggered by factors. NF- $\kappa B$ subsequently translocates into the nucleus, binding to a diversity of DNA sequences and beginning transcription of a large group of genes with a broad diversity of functions. It initiates transcripting multiple genes aiming to cell death suppression. Aberrant activation of NF- $\kappa \mathrm{B}$ is now confirmed to be associated with development of some malignant tumors..$^{4-8}$

With a goal to clarify the molecular mechanisms that underlie the biologic behavior of COCs and GCOCs, in the present work, we evaluated $\mathrm{NF}-\kappa \mathrm{B}$ immune-expression in a number of COCs and GCOCs. NF- $\mathrm{KB}$ showed cytoplasmic expression in COCs, and only patchy nuclear immunostaining, thus indicating $\mathrm{NF}-\kappa \mathrm{B}$ being inactive and may be rarely influencing the development of COC. There had been reports stating NF- $\kappa B$ was found mainly dormant in tooth germs, and in benign and malignant ameloblastoma where only scarce nuclear immunostaining was detected. ${ }^{8,9}$

On the other hand, another research results detected strong immunopositivity of NF- $\kappa \mathrm{B}$ in both ameloblastoma and ameloblastic carcinoma, thus indicating that $\mathrm{NF}-\kappa \mathrm{B}$ influence the progression of such odontogenic lesions and might play an oustanding role in their development. ${ }^{10}$

\section{Conflict of interest statement}

We declare having no professional nor any other personal interest of any kind in the review of the manuscript entitled.

\section{ACKNOWLEDGEMENT}

We would like to thank technical staff of department of Oral Pathology, Faculty of Dentistry, Alexandria University, for their unlimited and skilled technical assistance. No financial support of any kind has been received to accomplish this work.

\section{REFERENCES}

1- Speight P, Ledesma-Motes C, Wright J. Calcifying odontogenic cyst. In: El-Naggar AK, Chan JKC, Grandis JR, Takata T, Slootweg PJ (eds) WHO classification of Head and Neck Tumours, $4^{\text {th }}$ edition IARC, Lyon, pp 239- 241.

2- Goldenberg D, Sciubba J, Koch W, Tufano RP. Malignant odontogenic tumors: a 22-year-experience. Laryngoscope. 2004; 115: 1770-4.

3- Goldenberg D, Sciubba J, Koch W, Tufano RP. Odontogenic ghost cell carcinoma. Head Neck. 2004; 26: 378-81.

4- Yamanaka N, Morisaki T, Nakashima H, et al. Interleukin 1 beta enhances invasive ability of gastric carcinoma 
through nuclear factor-kappa B activation. Clin Cancer Res 2004; 10(5): 1853-9.

5- Shukla S, MacLennan GT, Fu P. Nuclear factor-kappaB/ p65 (Rel A) is constitutively activated in human prostate adenocarcinoma and correlates with disease progression. Neoplasia 2004; 6(4): 390-400.

6- Helbig G, Christopherson KW, Bhat-Nakshatri P. NF-jB promotes breast cancer cell migration and metastasis by inducing the expression of the chemokine receptor CXCR4. J Biol Chem 2003; 278:21631-8.

7- Zhang JL, Peng B, Chen XM. Expression of nuclear factor $\mathrm{jB}$, inducible nitric oxide sunthase, and vascular endothelial growth factor in adenoid cystic carcinoma of sali- vary and clinical outcome. Clin Cancer Res 2005; 11(20): $7334-43$.

8- Kumamoto H, Ooya K. Expression of tumor necrosis factor a, TNF-related apoptosis-inducing ligand, and their associated molecules in ameloblastomas. J Oral Pathol Med 2005; 34: 287-94.

9- Gong, Y., L. Wang, H. Wang, T. Li and X. Chen, 2009. The expression of NF- $\kappa \mathrm{B}, \mathrm{Ki}-67$ and MMP-9 in CCOT, DGCT and GCOC. Oral Oncol 2009; 45: 515-520.

10- Khater DS, Kasem RF and Morsy RA, 2017. Immunohistochemical Analysis of Nf- $\mathrm{BB}$ Expression and its Relation to Apoptosis and Proliferation in Different Odontogenic Tumors. Int J Cancer Res 2017; 13: 76-83. 